\title{
Subjetividad campesina y acumulación de capital en Sonsón, Antioquia: 1997-2020*
}

\author{
Diego Alejandro Morales Zapata \\ Facultad Latinoamericana de Ciencias Sociales, Quito, Ecuador \\ damoralesfl@flacso.edu.ec \\ https://orcid.org/0000-0001-5051-2539
}

\section{RESUMEN}

Este artículo problematiza el proceso de subjetivación campesina que tuvo lugar en Sonsón (Antioquia) entre 1997 y 2020 , dentro del contexto neoliberal de acumulación de capital que se produce en ese periodo. El artículo analiza la formación de una subjetividad subalterna en el campesinado. En este sentido, apela a dos teorizaciones sobre las relaciones sociales de poder y desigualdad tanto estructurales como culturales: los conceptos de hegemonía y subalternidad, según Antonio Gramsci; y el de acumulación por desposesión, desarrollado por David Harvey.

El enfoque metodológico utilizado en la investigación fue cualitativo, apoyado en el método etnográfico y complementado por análisis y revisión documental. La investigación postula que el modelo de acumulación desarrollado en Sonsón alrededor de la agroindustria del aguacate ha implicado relaciones de desposesión interiorizadas por los campesinos como una subjetividad subalterna de proletarización y emprendimiento.

Palabras clave: aguacate; campesinado; desposesión; emprendimiento; neoliberalismo; Sonsón; subalternidad.

Cómo citar: Morales Zapata, D. (2021). Subjetividad campesina y acumulación de capital en Sonsón Antioquia: 1997-2020. Ciencias Sociales y Educación, 10(20), 113-137. https://doi.org/10.22395/csye. v10n20a6

Recibido: 20 de enero de 2021.

Aprobado: 25 de marzo de 2021. 


\section{Farmer Subjectivity and Capital Accumulation in Sonsón, Antioquia: 1997-2020}

\section{ABSTRACT}

This article has as its central theme the process of peasant subjectivation in Sonson, Antioquia, between 1997 and 2020, within the neoliberal context of capital accumulation. It problematizes the formation of a subaltern subjectivity in the peasantry, appealing to two theories about social relations of power and inequality, both structural and cultural: the concepts of hegemony and subalternity, according to Antonio Gramsci, and that of accumulation by dispossession, as developed by David Harvey. The methodological approach used was qualitative with a mainly ethnographic method, complemented by documentary analysis and review. The research shows that the model of accumulation developed in Sonsón around the avocado agroindustry has implied dispossession relations, internalized by the peasants as a subaltern subjectivity of proletarianization and entrepreneurship.

Keywords: avocado; peasantry; dispossession; entrepreneurship; neoliberalism; Sonson; subalternity.

\section{Subjectividade camponesa e acumulação de capital em Sonsón, Antioquia: 1997-2020}

\section{RESUMO}

Este artigo centra-se no processo de subjectivação camponesa em Sonson-Antioquia entre 1997 e 2020, no contexto neoliberal da acumulação de capital. Problematiza a formação de uma subjectividade subalterna no campesinato, apelando a duas teorias sobre relações sociais de poder e desigualdade, tanto estruturais como culturais: os conceitos de hegemonia e subalternidade, segundo Antonio Gramsci, e o de acumulação por despossessão, tal como desenvolvido por David Harvey. A abordagem metodológica utilizada foi qualitativa com um método principalmente etnográfico, complementado por análise e revisão documental. A investigação mostra que o modelo de acumulação desenvolvido em Sonson em torno da agro-indústria do abacate tem implicado relações de despossessão, interiorizadas pelos camponeses como uma subjectividade subalterna de proletarização e empreendedorismo.

Palavras-chave: subalternidade; neoliberalismo; despossessão; campesinato; abacate, empreendedorismo. 


\section{Introducción}

Hasta hoy, la subjetividad antioqueña es un objeto en disputa disciplinar desde diferentes abordajes. Estos enfoques se dividen entre los que reproducen una versión hegemónica y los que, con diferentes énfasis, la someten a juicio. Los primeros tienen enfoques más subjetivistas, como el de Correa y Jaramillo (2002) sobre el papel del "ethos antioqueño" en la formación de empresas capitalistas; el de Betancur (1987), que es una oda al "modo de ser antioqueño"; o el de Téllez (2010), que exalta el papel de la colonización antioqueña para la competitividad nacional y regional. Los opuestos son fuertemente históricos, de sociología rural y economía política, suelen centrarse en los procesos de "colonización antioqueña" como formadores históricos de la ruralidad regional y nacional, que incluye la subjetividad que le es propia. Entre ellos destacan el de Tirado (1979), que señala las desigualdades propias de dicha colonización; el de Palacios (2009), que examina la formación de la economía cafetera; y el de Appelbaum (2007), que aporta una mirada a la subjetivación antioqueña desde la racialización.

Ahora bien, estas aproximaciones, con sus diferencias, se inscriben dentro de la conflictividad social y política-histórica de la sociedad antioqueña y colombiana como manifestación intelectual, académica y cultural, sin que en todos los casos sea fácil posicionarlas en dichos conflictos. Consideramos, en este sentido, que los procesos estructurales de acumulación de capital han formado objetivamente a los campesinos antioqueños como sujetos sociales y, al tiempo, han creado las condiciones del conflicto social en que las clases dirigentes - comerciantes, empresarios, industriales y terratenientes- edificaron la representación hegemónica del campesino regional que les permitió asimilarlos en ella política y culturalmente, con una pretensión universal, mediante el despliegue de fuertes dispositivos simbólicos de trabajo intelectual. Esta representación convirtió a la figura campesina hegemonizada en una piedra angular de la subjetividad regional. Así, se depositaron en la subjetividad campesina antioqueña rasgos funcionales a los intereses dominantes, como el ánimo de acumulación de riqueza, la laboriosidad abnegada, el conservadurismo, el blanqueamiento ${ }^{1}$, entre otros.

El problema de la construcción social de la subjetividad campesina en Antioquia es un proceso de identificación, asimilación y reconocimiento de sujetos subalternos hacia sus dirigentes, es decir, un proceso de subjetivación política definido por relaciones de desigualdad y poder históricamente

Según Virginia Gutiérrez de Pineda (1994), el blanqueamiento en Antioquia es a la vez una condición racial y económica: "Ello significa que Antioquia ha dado un vuelco en sus tradicionales prejuicios y la discriminación racial es hoy puramente económica: se es negro biológicamente por raza, pero por cultura se es "negro" por ausencia de riqueza. Vale decir, un negro con plata es blanco; un blanco sin dinero es un "negro" (p. 411). 
conflictivas. Este proceso ha dado lugar a la hegemonía de determinados sujetos sociales sobre otros a partir de una contradicción entre una posición objetiva en el mundo social y la consciencia sobre esta, que ha alimentado una correlación de fuerzas vigente a nivel regional y nacional.

Con esto presente, el municipio de Sonsón y los campesinos locales resultan importantes como espacio social y sujetos de estudio por dos razones fundamentales. La primera de ellas es su acumulado de vida y cultura campesina, que aún pervive y que deviene de su historia como centro del colonialismo antioqueño. La segunda es el desarrollo reciente de procesos de acumulación neoliberal, como la construcción de hidroeléctricas y la implantación de la agroindustria del aguacate, que se gestaron y crecieron en medio del conflicto social armado y que incluyeron la dimensión subjetiva del campesinado.

Este artículo propone, entonces, como parte de una investigación más amplia $^{2}$, que la transformación de la subjetividad campesina en Sonsón, a partir de la implantación del modelo neoliberal de acumulación y de la conflictividad social entre 1997 y 2020, especialmente mediante la eliminación de la oposición social a dicho modelo y con el desarrollo posterior de la agroindustria del aguacate, se ha caracterizado por la subalternidad como dimensión destacada de esta subjetividad.

Metodológicamente ${ }^{3}$, la investigación base fue de enfoque cualitativo con un método etnográfico nutrido por el análisis documental. Se realizaron veinte entrevistas semiestructuradas y no estructuradas a campesinos, intelectuales orgánicos, trabajadores de la cultura y habitantes de Sonsón. Por otro lado, tuvo lugar una revisión documental de archivos y prensa, lo que aportó información sobre los cambios en la organización económica rural de la subregión y el municipio. De este modo, las diferentes metodologías se llevaron a cabo en sinergia

2 Este artículo deriva de la tesis de maestría en sociología en la Facultad Latinoamericana de Ciencias Sociales (Flacso), Ecuador, denominada Imposición de la Subalternidad sobre el campesinado en el marco de procesos de acumulación y hegemonía. El caso del municipio de Sonsón, subregión del oriente de Antioquia (Colombia) 1997-2020. El trabajo de campo tuvo lugar en dicho municipio y actualmente (abril de 2021) la tesis se encuentra aprobada.

3 Las entrevistas en la investigación base se disgregaron de la siguiente manera: once fueron hechas a campesinos de Sonsón y nueve a intelectuales locales o trabajadores de la cultura, según la definición gramsciana. La revisión documental se realizó principalmente en fuentes oficiales accesibles como las bibliotecas y archivos públicos del municipio de Sonsón. La investigación se centró en la producción cultural y artística. Se analizaron textos entre los que se encuentran etnografías y trabajos sobre la vida rural local, bibliografía sobre el conflicto armado en el municipio, informes de prensa y datos oficiales sobre el cultivo de aguacate, teniendo como criterio de selección temporal el periodo 1997-2020. Todo el trabajo de campo tuvo lugar entre enero y marzo de 2020. En el caso de las entrevistas se siguieron los protocolos éticos de la investigación y, mediante consentimiento informado, la mayoría de las personas autorizaron la publicación de sus nombres y otras participaron de manera anónima. 
para responder a una indagación sobre la relación conflictiva entre subjetividad y estructura económica.

Luego de esta introducción, se presenta la fundamentación teórica de la investigación basada en las elaboraciones conceptuales de David Harvey, Massimo Modonesi y Antonio Gramsci. En segundo lugar, se expone una contextualización histórica sobre la formación del sujeto campesino en la región antioqueña. En tercer lugar, se analiza la estructura económica de Sonsón y su relación con la subjetividad campesina, durante el periodo 1997 y 2020, teniendo como eje la agroindustria aguacatera. Finalmente, se examina la transformación de dicha subjetividad desde la perspectiva de la subalternidad. El artículo concluye respondiendo a la pregunta por los cambios en dicha subjetividad. En este sentido, plantea una relación entre algunos de sus rasgos y el proceso reciente de acumulación neoliberal manifiesto a nivel local, además de sugerir algunos aportes de esta investigación al debate en que se inserta.

\section{Desposesión y subalternidad}

El punto de partida teórico de este trabajo es una comprensión de la sociedad en que la práctica social de los sujetos, principalmente en la que se establecen las relaciones sociales para la producción y reproducción de la vida material, es el asiento en el que crecen y desarrollan las otras dimensiones de la vida social como la cultura, la ideología, la religión, la política o las relaciones jurídicas. De esta manera, este trabajo se distancia de las lecturas de la subjetividad en general, y antioqueña en particular, que explican la organización económica de la sociedad como resultado de la voluntad y consciencia de los sujetos (Correa y Jaramillo, 2002; Téllez 2010).

En segundo lugar, la subjetividad, la cultura y en general de las representaciones sociales no son entendidas aquí como meras derivaciones de las relaciones materiales. Al contrario, estas se configuran y son intervenidas desde una perspectiva histórica que da forma a las clases como sujetos sociales primordiales sobre los individuos. El papel de estos últimos siempre está en función del grupo social al que adhieren.

Ahora bien, la enunciación de la clase como sujeto central de esta investigación, específicamente el campesinado, remite a una comprensión de las relaciones sociales que da cuenta de su conflictividad, más que de su armonía. El abordaje desde la perspectiva del conflicto social es necesario para centrarse en cuestiones como la distribución de la tierra y los recursos naturales, los flujos campo-ciudad o las luchas armadas e ideológicas. 
A modo de posicionamiento, el lector no puede esperar encontrar la ficción de la neutralidad valorativa en este trabajo. Al partir del conflicto social, tiene ante sí un esfuerzo comprometido por elaborar la experiencia en el mundo social del campesinado como clase subalterna y despojada. Este punto de partida controvierte la versión social e institucionalmente autorizada y reproducida sobre este sujeto social.

Estos presupuestos epistemológicos, en especial la comprensión de la realidad social a partir de la distinción entre su base material y las representaciones sobre ella elaboradas, alumbran la articulación de los dos referentes teóricos aquí principales: Antonio Gramsci y David Harvey, así como la forma posterior de exponer los resultados en dos bloques que obedecen a esta lógica. Tal fundamentación teórica, sumada a la exposición sobre las condiciones empíricas de formación histórica del sujeto campesino en Antioquia, permiten entender la pertinencia de estos dos referentes para atender al problema planteado y discutir con sus abordajes descritos.

\section{Acumulación por desposesión}

Las transformaciones económicas en Sonsón entre 1997 y 2020, así como su impacto en la vida campesina, se abordan desde el aporte teórico que hace el economista y geógrafo norteamericano David Harvey al concepto conocido en la tradición marxista como acumulación primigenia y que denomina acumulación por desposesión.

Este concepto de acumulación primigenia permite explicar, desde una perspectiva histórica, la gestación de la sociedad capitalista y, sobre todo, de relaciones que le son distintivas, como el régimen de trabajo asalariado, la subsunción del campo a la ciudad, la concentración de la propiedad y la privación de medios de producción como la tierra a la masa de trabajadores. Marx (1974) lo formula en el capítulo XXIV del libro 1 de El Capital. Crítica de la economía política cuando describe las luchas de apropiación burguesa de las tierras comunes y campesinas en Inglaterra durante el siglo XVI que desembocaron en: i) la expropiación de los campesinos para proveer fuerza de trabajo a las nacientes industrias urbanas y convertir sus parcelas en pastos para el ganado; ii) el crecimiento de población en condición de vagancia; iii) los cercamientos; iv) y, en general, la sujeción del campo a los centros urbanos y de comercio. Todo este proceso fue llevado a cabo por la burguesía naciente, algunos terratenientes y el Estado.

El concepto pasaría desde entonces por múltiples redefiniciones, pero conservando su esencia. Rosa Luxemburgo (1912) introduce una dimensión geográfica al concepto cuando piensa el proceso de acumulación originaria en el marco de 
la acumulación ampliada del capital, en la que el imperialismo y el colonialismo europeo se han enfrentado con formas de organización social aún no sometidas al capital. El aporte resulta importante porque abre la posibilidad de pensar la inserción de relaciones capitalistas en contextos no céntricos, es decir, su movilidad global. De esta manera, se generan cambios como la reprimarización de la economía mediante los monocultivos, sin dejar de lado el papel de la violencia.

Recientemente, Silvia Federici (2010) integra la teoría feminista y el concepto de acumulación por desposesión en su análisis del papel de la mujer en la transición feudalismo-capitalismo. Su atención está en el trabajo no remunerado de la mujer para la reproducción de la fuerza de trabajo como condición de la explotación del hombre, y en su diferencial perjuicio por los cercamientos de las tierras comunes en Europa, procesos que significaron para las mujeres la desposesión de la autonomía sobre su cuerpo.

Ahora bien, específicamente el desarrollo que hace David Harvey (2005) al concepto de acumulación originaria (renombrándolo acumulación por desposesión) resulta pertinente para este trabajo por diversos motivos. En primer lugar, Harvey extiende su alcance al periodo neoliberal (contemporáneo) de acumulación de capital y no lo considera solo como momento de génesis o parto, como lo hace Marx. Para el autor norteamericano, la acumulación por desposesión es un proceso permanente con que, en el marco de la acumulación ampliada (global) del capital, se solventan sus crisis. La perspectiva geográfica crítica de Harvey destaca cómo la debacle de centros históricos de acumulación (Norteamérica y Europa) relocaliza el capital en países, actividades y zonas más favorables a su reproducción, generalmente Latinoamérica, África y parte de Asia. Esto genera un choque permanente con formas de vida, culturas y economías menos articuladas y dependientes del capital a nivel internacional, frecuentemente indígenas y campesinas. Como señala Harvey (2005):

La reciente depredación de los bienes ambientales globales (tierra, aire, agua) y la proliferación de la degradación ambiental, que impide cualquier cosa menos los modos capital-intensivos de producción agrícola, han resultado de la total transformación de la naturaleza en mercancía. La mercantilización de las formas culturales, las historias y la creatividad intelectual supone la total desposesión -la industria de la música se destaca por la apropiación y explotación de la cultura y la creatividad populares. La corporativización y privatización de activos previamente públicos (como las universidades), por no mencionar la ola de privatización del agua y otros servicios públicos que ha arrasado el mundo, constituye una nueva ola de "cercamiento de los bienes comunes". Como en el pasado, el poder del Estado es usado frecuentemente para forzar estos procesos, incluso en contra de la voluntad popular. Como también sucedió en el pasado, estos procesos de desposesión están provocando amplia resistencia, de esto se trata el movimiento antiglobalización. (pp. 114-115) 
Por otro lado, este desplazamiento del capital no es solo geográfico, sino productivo. Las economías en que se asienta suelen reprimarizarse. Las consecuencias sociales y ambientales que ello tiene, al volcarse al extractivismo para el mercado internacional en bienes como minerales, petróleo o agroindustriales, afectan especialmente a la ruralidad y los sujetos que la habitan.

Este mecanismo de acumulación capitalista para solventar la crisis se caracteriza por apalancarse en procesos políticos, específicamente de violencia y coerción, a manos de agentes privados como empresas, pero también del mismo Estado o paramilitares. Estos arremeten contra poblaciones o sujetos que generan algún tipo de resistencia y que terminan siendo despojados violentamente de los medios para la reproducción de su vida material e inmaterial. Así, estos medios pasan a ser propiedad blanqueada (legalizada) de las clases dominantes: empresarios, industriales y comerciantes bajo diferentes formas.

\section{Subalternidad y subjetividad}

Dentro de esta perspectiva teórica, la subjetividad aparece como una interiorización de la experiencia objetiva en el mundo social que tiene los sujetos, especialmente la del conflicto. Se trata de un proceso está mediado por las relaciones de poder culturales e ideológicas que le dan forma. Esta aproximación teórica deriva de los conceptos que se recogen de Antonio Gramsci: hegemonía y subalternidad, en su formulación por Massimo Modonesi (2010) relativa a la subjetividad. Se considera su carácter orgánico, es decir, su interdependencia teórica.

En el pensamiento de Gramsci (2013), el concepto de hegemonía se refiere a la subjetivación o interiorización de una determinada concepción del mundo por diferentes sujetos sociales, así como a la formación de la unidad orgánica nacional a partir de un proyecto político y a la dirección política, intelectual y moral. Todas estas son todas formas de expresar la misma cuestión. Este concepto es formulado por el autor italiano a partir del problema empírico que denomina "cuestión meridional", esto es, la coexistencia de una empobrecida masa campesina en el sur de Italia frente a un norte industrial y la manera en que los campesinos del sur sirvieron voluntariamente a la represión, en la década de 1920, contra las huelgas obreras en el norte. La respuesta que aporta es la hegemonía. Este concepto se refiera a la adopción por parte de una clase de una concepción del mundo que no les es propia o no refleja su experiencia en el mundo social. Los intelectuales de las clases dirigentes (principalmente religiosos en su estudio), mediante trabajo cultural, integraban en la visión del mundo de terratenientes y burgueses a los campesinos pobres y los enfrentaban a los obreros comunistas del norte de Italia. 
Para Gramsci (1967), los intelectuales orgánicos son aquellos que inscriben su trabajo en función de los intereses y concepción del mundo de una clase social. Mediante su producción cultural, unifican en un proyecto nacional oligárquico o nacional popular, según sea el caso, a aquellas clases no antagónicas, es decir, generan consenso, identidad y reconocimiento. Este direccionamiento político, que es al mismo tiempo intelectual, moral, cultural e ideológico, forma la subjetividad y a los mismos sujetos sociales, en términos de su práctica, como interiorización de una experiencia en el mundo social (sociedad capitalista) (Modonesi, 2010).

Al tratarse de una relación social de poder, es decir, de desigualdad que no se reduce a la dominación, sino que genera consenso, el otro extremo del sujeto hegemónico es el subalterno. La subalternidad, como subjetividad, es la aceptación de una condición de inferioridad y la introyección de una visión ajena del mundo. El subalterno carece de autonomía, de capacidad de formular un proyecto propio al conjunto de la sociedad y de comportarse como clase. Por lo tanto, es dirigido política e intelectualmente y no se reconoce en quienes comparten su condición objetiva de explotación u opresión. Al contrario, rompe con ellos. Puede ser ejemplificado como aquel trabajador que se identifica con su patrón más que con otros trabajadores. Se trata, pues, de la interiorización de una relación de poder en la que se es parte subalterna:

\footnotetext{
Después de Gramsci, ninguna reflexión sobre el conflicto y la emancipación puede restar importancia a la subalternidad como expresión y contraparte de la dominación encarnada o incorporada en los sujetos oprimidos, base y, por ende, punto de partida ineludible de todo proceso de conflicto y emancipación. (Modonesi, 2010, p. 30)
}

Ahora bien, todo esto hace clara la disección que, con fines comprensivos, hace Modonesi (2010) de las categorías de Gramsci para entender la subjetividad. Antagonismo, subalternidad y autonomía forman, para el autor, dimensiones contingentes de la subjetividad, es decir, nunca son absolutas y el hecho de que una prime sobre las otras depende de la correlación de fuerzas en la lucha hegemónica y contrahegemónica. Las tres expresan momentos experimentados por los sujetos sociales en esta lucha: rebeldía, sumisión y emancipación, respectivamente. En este sentido, afirma Modonesi (2010):

Sostengo, por el contrario, la posibilidad de articularlos, reconociendo

un nivel de homología teórica entre ellos que, junto a la especificidad de cada uno, permite configurar una triada categorial, un enfoque tripartito en donde subalternidad, antagonismo y autonomía resultan complementarios en la medida en que iluminan tanto una dimensión y un aspecto simultáneo — sincrónico—así como un pasaje significativo que permite hilar una lectura procesual diacrónica. (p. 18) 
Con esto presente, es posible ver las eventuales conexiones entre las dos propuestas teóricas planteadas. La formación de una subjetividad subalterna en el campesinado de Sonsón podría entenderse como un proceso de desposesión de las otras dos dimensiones: antagonismo y autonomía. Todo esto significa un esfuerzo hegemónico afirmativo en el marco del proceso neoliberal de acumulación de capital, lo que sería la integración de las trasformaciones en la estructura económica de una sociedad y la transformaciones culturales, ideológicas y subjetivas que se encarnan en sujetos campesinos.

\section{Génesis y desarrollo del sujeto social campesino en Antioquia}

Desde el punto de vista sociológico, la formación del campesinado como sujeto social en la región antioqueña debe ser entendida en el marco del proyecto de modernización capitalista a nivel nacional. Históricamente, la sujeción del campo a la ciudad en Colombia y la región, aunque hunde sus raíces en el periodo colonial, inicia en el siglo XIX y su principal manifestación son las oleadas de colonialismo antioqueño ${ }^{4}$. Estas están marcadas por una profunda conflictividad social y relaciones de desigualdad, especialmente en cuanto a la apropiación de la tierra. Según Tirado (1979), este proceso económico y cultural tuvo como punto de partida el sometimiento que industriales y comerciantes, enriquecidos mediante actividades como la minería, ejercieron con el apoyo estatal sobre la población desclasada. La forzaron a colonizar territorios aún inexplotados $u$ ocupados por pueblos afros e indígenas, en donde los colonos se asentaron y se hicieron campesinos, para posteriormente ser expropiados por terratenientes, comerciantes e industriales.

Desde finales del siglo XIX hasta mediados del siglo XX, el desarrollo la economía cafetera motivó una segunda oleada colonialista antioqueña sobre Caldas y el norte del Valle del Cauca. Esta se caracterizó por el asentamiento de los colonos-campesinos en las tierras altas montañosas luego de sufrir el despojo de terratenientes fuertemente articulados con la industria de centros regionales de acumulación como Medellín, Río Negro o Santa Fe de Antioquia. Así, como lo describe Palacios (2009), se formó la agricultura cafetera familiar de pequeños propietarios situados en las estribaciones de la cordillera central y occidental principalmente:

El despegue tardío hacia una economía de base cafetera fue a la postre vital para que sobreviviera y aun se multiplicara la finca familiar. En estas regiones, a diferencia de las que hemos estudiado, la influencia de las haciendas como centros de difusión y dominio de la agricultura del café fue moderada. Los colonizadores

En su trabajo Dos plazas y una nación: raza y colonización en Río Sucio Caldas, la historiadora Nancy P. Appelbaum (2007) debate el uso hegemónico del término "colonización" como categoría autorizada que oculta la violencia del proceso al que prefiere describir como "colonialismo". 
capitalistas se preocuparon inicialmente por acaparar las tierras bajas y de fácil acceso, y dejaron a los colonos pobres los bosques escarpados y alejados que con el tiempo se transformarían en las tierras más productivas y económicamente las más adecuadas para cultivar café. (Palacios, 2009, p. 286)

A partir de la segunda mitad del siglo XX el campesinado antioqueño enfrenta la paulatina crisis de la economía cafetera motivada por el desmonte de los acuerdos internacionales para la estabilidad de los precios, lo que situó, entre otras, a la subregión del oriente de Antioquia (donde se encuentra Sonsón) en el ojo de los intereses para procesos de acumulación de capital, que se conocerían como neoliberales ${ }^{5}$, en América Latina: mercantilización del agua para la explotación hidroeléctrica, desarrollo de la producción agroindustrial, imposición del turismo, supeditación económica local a mercados externos, entre otros. Estos procesos han estado marcados por la desposesión campesina y la destrucción-creación de una ruralidad a imagen y semejanza de las necesidades del capital insertado.

A la par, la subregión experimentó significativamente la conflictividad social dentro de la "normalidad" civil y su superación por la conflictividad bélica. Así lo expresa Olaya (2016) en su estudio sobre el Movimiento Cívico de Oriente y su lucha contra las Empresas Públicas de Medellín. Asimismo, trabajos como los de Arbeláez (2007) y Siegert y de la Torre (2011) se ocupan de la confrontación armada en la subregión. Entre otras cosas, describen la represión a los movimientos sociales, la inserción de las guerrillas y la posterior pacificación llevada a cabo por el Estado y el paramilitarismo, que significaría la eliminación de organizaciones de izquierda tanto armadas como no armadas. La ruralidad como espacio social ha sido preponderante, aunque no exclusiva, en la conflictividad social. Si se consideran las particularidades históricas de Sonsón y la subregión, el campesinado como sujeto social tiene una posición de especial relevancia dentro de los conflictos en sus diferentes dimensiones.

Desde la década de los noventa hasta la actualidad, la base de conflictividad social, política y armada en la subregión, así como su pacificación violenta, ha sido, siguiendo a Siegert y de la Torre (2011), la articulación forzada del oriente al capital y los intereses externos (proceso que se encuentra en pleno auge en Sonsón). Este hecho está asociado a obras de infraestructura, garantías a los flujos de mercancías y satisfacción de la demanda externa de alimentos. Se trata del periodo más álgido de la conflictividad social, el cual estuvo marcado por fenómenos como el abandono de tierras, el desplazamiento obligado, las desapariciones forzadas y las masacres. Estos hechos se inscriben en las

Harvey (2005) trata el neoliberalismo como una reedición de procesos de acumulación basados en la desposesión de bienes comunes y en la destrucción creativa del espacio y las condiciones para la reproducción del capital, tanto sociales como económicas. 
regularidades del conflicto colombiano, pero también del despliegue de la economía neoliberal a nivel local:

Esta subregión, dedicada tradicionalmente a la agricultura campesina de autoconsumo y de abastecimiento del centro del departamento, se va acoplando a la expansión de la industria centrada en el Valle de Aburrá y en los proyectos nacionales de electrificación y comunicación vial. De un lado, la expansión de la industria del Valle de Aburrá profundiza la ruptura entre un altiplano industrializado y urbanizado en torno suyo y una amplia zona periférica en sentido socioeconómico y político. Del otro, la realización de megaproyectos de infraestructura que no respondían a procesos endógenos de la región sino a exigencias de alcance nacional, como el complejo hidroeléctrico, la autopista Medellín-Bogotá, el aeropuerto y zona franca de Rionegro, redefinen la geografía del oriente. El oriente queda así más vinculado al centro del departamento y a la economía nacional y mundial, mientras su economía se urbaniza y terceriza. Por eso el nuevo desarrollo de la región se concentra en unos pocos municipios del altiplano, a pesar de que las hidroeléctricas están situadas en la vertiente oriental y que la autopista Medellín-Bogotá atraviesa toda la región. (Siegert y de la Torre, 2011, p. 15)

En cualquier caso, una de las dimensiones menos exploradas de estas luchas sociales tiene que ver con las subjetividades, las representaciones del mundo social y la manera en que se establecen los límites de su interpretación. Precisamente, el presente trabajo trata de realizar un aporte en esa dirección al sugerir una mirada desde el conflicto y la estructura económica.

\section{Frenesí aguacatero y subjetividad}

Durante las dos últimas décadas se han desarrollado o acentuado dos características principales en la subjetividad de los campesinos de Sonsón: la decidida "vocación" emprendedora en el sentido del emprendimiento capitalista, como una práctica social empresarial en la ruralidad, y el convencimiento de los beneficios del trabajo asalariado con todas sus características como la individualización. Estos rasgos se han hecho preponderantes a partir del desarrollo local de formas de acumulación neoliberales, especialmente de la agroindustria aguacatera como eje central de diversas formas de desposesión sobre los campesinos, lo que produce su proletarización y descomposición. Veamos cómo estos procesos estructurales han forjado de tal manera esta subjetividad.

El desarrollo significativo de la agroindustria aguacatera en Sonsón es relativamente reciente, puede datarse de alrededor de 2015. Hay dos procesos que permiten entender su desarrollo. Uno de ellos lo antecede y lo ha empujado: el conflicto armado. El otro le es paralelo: la articulación dependiente de la economía local al mercado internacional de alimentos. El primero es fundamentalmente político; se trata del aniquilamiento por el Estado y grupos paramilitares, a nivel local y regional, de todas las formas de resistencia contra los intereses 
y proyectos del capital internacional (frecuente ligado al capital nacional) que llegaron a ser ejercidas tanto por movimientos sociales como por el Movimiento Cívico de Oriente y por la insurgencia armada, específicamente las FARC-EP y el ELN en las últimas décadas. Considerando diferencialmente sus acciones de resistencia en el tiempo y en cada municipio, este proceso de lucha se consolida a favor de las clases dominantes alrededor de 2010.

Específicamente, las acciones de sabotaje guerrillero contra las condiciones de reproducción del capital, tales como el comercio, la infraestructura, la circulación de mercancías o los ataques hacia los mismos terratenientes y capitalistas locales, representaban un obstáculo al desarrollo de la economía neoliberal. Paulatinamente, el Estado y el paramilitarismo expulsaron a las guerrillas de Sonsón y el oriente de Antioquia. Esta represión se extendió a los movimientos sociales civiles de izquierda mediante su proscripción de facto.

José Luis Blandón es un líder campesino de Sonsón que, sobre la explotación hidroeléctrica que hoy sufre su vereda y que se desarrolló con posterioridad al conflicto, recuerda algo que ejemplifica esta cuestión: "Eso de la hidroeléctrica ya venía hace tiempo, eso fue porque la guerrilla secuestró al ingeniero y ahí se frenó" (J. Blandón, comunicación personal, 13 de marzo de 2020).

Por otro lado, el conflicto armado creó directa o indirectamente el vaciamiento de la tierra necesaria para la inserción del capital en el territorio, bien sea por su despojo directo, abandono o por hacer paulatinamente imposible la continuidad de la vida campesina. Evidentemente, el vaciamiento de la tierra genera proletarización campesina por la vía de hacer al sujeto campesino un asalariado (rural o urbano) al despojarlo de su medio de producción (la tierra) o estrangular paulatinamente las posibilidades de crecimiento de su economía para conducirlos a vender la tierra, algo altamente favorable a la agroindustria. Esto quiere decir que la transformación en la correlación de fuerzas favorable a los agentes del capital internacional -empresarios, multinacionales, comerciantes y banqueros- resultante del conflicto, creó las posibilidades objetivas para el desarrollo de la economía neoliberal en el municipio, que despegarían a plenitud más adelante. En su trabajo etnográfico conjunto, Vega y las comunidades campesinas de Río Verde en Sonsón (2019) describen esta problemática:

En 2010 el conflicto disminuyó y algunos de los que se habían ido volvieron [...] No obstante las condiciones para vivir por aquí han ido cambiando. Nuestra población ha disminuido y cada vez es más difícil encontrar con quién sembrar el campo [...] la familia se ha mermado; ya no es época de tener 14 o 15 hijos, máximo son $1 \circ 2$. Hay personas muy trabajadoras, pero son ancianos que están colgando los guayos o que ya no son capaces de trabajar [...] Por su parte los jóvenes también se han ido yendo por falta de oportunidades educativas y económicas o porque ya son de otro ambiente. Ellos prefieren irse a trabajar a los cultivos de aguacate de 
las veredas Tasajo o Llanadas, porque los vinculan y les dan un sueldo [...] Por si fuera poco, debido al conflicto armado y la disminución de la población, las tierras que trabajábamos han disminuido. Antes había mucho trabajadero con café, caña, animales y otros cultivos. Hoy, parte de eso se ha perdido en el monte, es puro rastrojerío. Hay áreas donde no hay ni la mitad de destapado de lo que había abierto hace 15 años. Y si a eso se le suma que no hay con quien sembrar, recoger o moler, hay personas a las que les toca dejar perder la finca. (p. 65)

Ahora bien, este proceso también implicó la creación de condiciones subjetivas favorables al capital. Al eliminar los sujetos que resistían social y políticamente a las iniciativas neoliberales, se destruyeron concepciones del mundo, demandas, acervos culturales y, sobre todo, potencialidades de la subjetividad no funcionales al nuevo momento de acumulación. Así, se dejó un vacío que luego pudiera ser llenado con una subjetividad que sí cumpliera esta demanda, es decir, una subjetividad campesina fundamentalmente empresarial subalterna. El trabajo de Arbeláez (2007) sobre el desplazamiento forzado en el oriente de Antioquia da cuenta de ello cuando señala el arrasamiento paramilitar de las cooperativas agrícolas auspiciadas por la Unión Patriótica en veredas de Granada y San Rafael. Por su parte, Siegert y de la Torre (2011) exponen en su trabajo comparativo sobre el conflicto armado en Urabá y el oriente de Antioquia que

en el Oriente antioqueño se construye un sentido del lugar desde abajo, a partir de los sectores pequeños y medios de las localidades y a través de una actuación colectiva de buena parte de las localidades que lo conforman. Es un sentido del lugar que se forja en cuatro años de movilización social y deja honda huella en la memoria colectiva de sus habitantes, de sus líderes sobrevivientes y hasta de integrantes del ELN que en la guerra actual aducen su pertenencia a ese oriente, su participación en el movimiento social de entonces y su decisión de haber conformado las filas del grupo armado ante su frustración por el aplastamiento paramilitar de cualquier alternativa política. (p. 51)

El segundo proceso mencionado (o nuevo momento), la subsunción de la economía campesina de Sonsón en el mercado internacional (prácticamente toda la economía local), es marcadamente estructural. Pero esta va creando una subjetividad subalterna. Su encarnación es la implantación de la agroindustria del aguacate como eje articulador de otras formas de despojo que recaen sobre los campesinos de Sonsón y se refuerzan entre sí.

La producción local de aguacate para la exportación ha sido fuertemente impulsada por alcaldías municipales y multinacionales, entre las que destacan las chilenas ${ }^{6}$, que están en un proceso creciente de compra de tierras e impulso

Según la población de Sonsón, los mayores compradores de tierras locales para el cultivo de aguacate son empresas chilenas. Desde la perspectiva geográfica de la acumulación que plantea Harvey, esto no es un detalle irrelevante si se tienen en cuenta los conflictos sociales por el agua que presionan en Chile la relocalización 
del cultivo en los campesinos. Los datos presentados en la página web oficial de la Alcaldía municipal dan cuenta de ello:

\begin{abstract}
Al respecto, se estima que, en dos periodos administrativos, es decir, que, en aproximadamente 8 años, Sonsón cuente con unas 4.000 mil hectáreas nuevas establecidas de aguacate hass, hecho histórico para el municipio; constituyéndolo como un epicentro de producción agrícola y potencial generador de economías sostenibles, pasando a ser un escenario pertinente para la inversión nacional e internacional [...] En Sonsón se tiene registrados 485 predios con cultivos establecidos de aguacate hass; de éstos, 23 se encuentran certificados por el ICA y, 120 están en trámite [...] Teniendo en cuenta que Sonsón está adquiriendo esta vocación, respecto al potencial agrícola con productos de alto valor exportable como el aguacate hass, cerca de 12 comercializadoras nacionales e internacionales, entre las que se destacan: West Sole, Aguacate Gourmet, Hass Colombia, FLP, Green West, Cartama, La Perla, Frutireyes, Ocati, Nativa Produce y Caribbean Exotics, entre otras, han puesto la mirada en este municipio del oriente antioqueño, desde varias perspectivas, que van desde la adquisición de predios para el establecimiento tecnificado de este cultivo, hasta la compra del producto a las familias campesinas que avanzan en la implementación de buenas prácticas y certificados de predios exportadores; con esto, se está potenciando las fuentes de empleo e ingreso para cientos de familias sonsoneñas y de la región. (Ospina, 2017)
\end{abstract}

En primer lugar, la compra de tierras opera como una forma de desposesión sobre los campesinos que los priva de su medio de producción fundamental. Se apoya tanto en la separación económica y subjetiva de la tierra, causada en el conflicto, como en la histórica precariedad rural nacional. Ambas particularidades le sirven de precondición favorable, lo que hace que los campesinos sean proclives a vender y permitan que las multinacionales y empresarios nacionales interesados en invertir en el cultivo se vayan apropiando de la tierra. Las multinacionales productoras, algunas exportadoras y los empresarios compran las fincas de los campesinos, dependiendo de condiciones como el agua disponible, nivel previo de explotación y vías de comunicación, en 200 millones de pesos colombianos (60.000 USD aproximadamente en 2020) y siempre tratan de sumar varias para formar una sola gran extensión de cultivo.

Esta forma de despojo se beneficia del deseo que tienen muchos campesinos de proletarizarse en condiciones normales que nunca han gozado: prestaciones sociales, salario fijo y jornada laboral menor a la que su trabajo propio les obliga. Esto es algo que las multinacionales que compran la tierra les permiten eventualmente al hacerlos sus asalariados, lo que da luces sobre el origen de la "dedicación al trabajo" en la subjetividad campesina antioqueña. En este sentido, esta puede ser entendida como expresión subalterna construida a partir de la desposesión.

del capital para la producción de aguacate (que consume bastas cantidades de agua) en sitios como Sonsón, que cuenta con bastas fuentes de agua (incluyendo un páramo) y puertas abiertas. 
No obstante, existen campesinos que no se dan fácilmente a la venta de la tierra y a trabajar para el comprador. Para ellos está reservado el camino del emprendimiento, en el que se asumen a sí mismos como empresarios. Pero, como se verá, lleva igualmente a la proletarización.

La inserción de la agroindustria aguacatera actúa como forma de acumulación y despojo de otros modos, especialmente para quienes aún tienen tierra (que tienden a perderla), pero que, además, van siendo despojados de su autonomía productiva. Esta forma de desposesión se basa en los cambios en el mercado determinados por el auge de productos para la exportación (incremento de la demanda) y el asentamiento a nivel local de nuevos agentes comerciales y productores externos. Todo ello impulsa la explotación intensiva del suelo y el uso intensivo de pesticidas y fertilizantes no orgánicos. El temor a que los productos tradicionales de los campesinos, como la papa, caña o frutales no encuentren en el mercado suficiente demanda es para ellos una obligada dedicación al aguacate y otros productos como la curuba, la uchuva o el higo, destinados principalmente al mercado internacional. Así, su aventura empresarial nace del miedo y la imposición, más que de un ánimo natural emprendedor.

En este proceso de despojo, el campesino no solo pierde algo material como la tierra. En realidad, lo que pierde es su relativa autonomía productiva expresada en prácticas tradicionales y la capacidad de decidir qué y cómo producir. Esta autonomía se transfiere, ante el aumento de la demanda internacional, a los agentes del mercado externo: empresarios, comerciantes y multinacionales, terminando el campesino como su subalterno. Esta situación es descrita por Alberto Hincapié 7 , un campesino de Sonsón que, con setenta y tres años, experimentó la toma de poder del mercado sobre la vida campesina, especialmente en cuanto a su producción: incremento de plagas y uso de pesticidas, imposición de estándares estéticos sobre la producción de papa "lisita y blanquisita", uso obligado de semillas certificadas por el Instituto Colombiano Agropecuario (ICA) y la pérdida de las tradicionales, entre otros.

Así, ante la privación de la capacidad de decidir qué producir, el campesino se ve abocado a producir "lo que está dando", esto es, emprender dentro de la lógica capitalista y a pesar de ella. De un modo más crudo, esto ubica el origen de la gran virtud "emprendedora" campesina en un proceso social y económico menos romántico y como una adaptación a este.

En este caso, como en otros dentro de la investigación, las condiciones propias del trabajo de campo etnográfico como el ruido externo o la no disposición voluntaria e informada de la persona entrevista a ser grabada, según los protocolos éticos de la investigación, impidieron realizar un registro en audio, por lo que se trabajó con notas de campo y no con una transcripción literal. 
Para lanzarse a la lucha por el éxito en el mercado de alimentos, los campesinos de Sonsón deben, en primer lugar, contraer obligaciones que les resultan otra forma de desposesión: el endeudamiento con bancos, instituciones financieras intermedias o prestamistas particulares. Martín Estrada trabaja como cobrador para una agencia financiera local en Sonsón; por ello, escucha permanentemente los lamentos campesinos sobre este problema:

Muchas veces los campesinos siembran lo que está dando y después cuando el precio baja se quiebran. Tengo un cliente que le debe a todo el mundo y se tuvo que ir para Medellín, porque si por ejemplo la papa criolla, que estaba a $300 \mathrm{mil}$ la carga [125 kg] y bajó a 50 mil, pero a usted para sacar lo que tiene, tiene que pagar de recogida y el transporte y eso le vale más de lo que le dan, usted deja eso ahí a que se pierda. Hay un banco de alimentos, que lo que hace es ir a recoger eso gratis y se lo regalan a los pobres. (Martín Estrada, comunicación personal, 20 de febrero 2020)

En los últimos veinte años ha crecido exponencialmente el sector financiero en el municipio, principalmente proveyendo capital mediante préstamos a campesinos para la adecuación productiva que exige el mercado mundial. Microempresas de Colombia, una de las entidades financieras asentadas allí, visualizó así sus oportunidades de negocio a través de un estudio prospectivo en 2019:

Las condiciones y dinámica económica del municipio, influye en las tendencias hacia el consumo de productos financieros de ahorro y crédito. Sonsón es un municipio con una vocación agrícola tradicional, donde los cultivos de café, cacao, caña, papa y cultivos que tienen gran importancia en mercados internacionales, como el aguacate, higo, y otras frutas, son la base fuerte de la economía del municipio, igualmente la ganadería y la minería con la producción de mármol caliza y explotación de oro, enriquecen y diversifican la economía de Sonsón. (Microempresas de Colombia 2019, p. 35)

El endeudamiento campesino es favorecido con la dulce propaganda de los agentes financieros que describen las mejores condiciones posibles para los préstamos. El capital financiero se pone en marcha dentro las fincas de diferentes maneras: infraestructura para la producción, trabajo, medios de transporte o adecuación de suelos. Hecha la inversión, por ejemplo, para producir aguacate, el campesino reduce o elimina totalmente su producción de autoconsumo y dedica la mejor y mayor parte de su finca al cultivo para el mercado, pero este tarda cuatro años en dar frutos. Mientras tanto, el emprendedor rural debe proletarizarse para poder sobrevivir y cumplir los pagos de la deuda. Al proletarizarse o trabajar como jornalero, corre el riesgo de no poder cuidar el cultivo para el que se endeudó y con ello fracasar en su emprendimiento. A lo anterior, se suman amenazas a las que el campesino aventurado en su empresa capitalista es especialmente sensible: el cambio climático y las plagas que no 
puede controlar asolan su cultivo y frecuentemente le hacen perder la cosecha total o parcialmente.

Existe un tipo de peligro que el campesino emprendedor asume y que es permanente: la competencia en el mercado. Hay dos dimensiones de esta competencia: entre campesinos y multinacionales y entre los propios campesinos. En el primer caso, empresarios, multinacionales y campesinos aspiran exportar la mayor parte de su producción. Pero, en la práctica, la cantidad que no cumple con los estándares por defectos de calidad e incluso estéticos es destinada al mercado nacional. Los problemas para el campesino empeoran cuando, por su menor nivel comparativo de inversión, debe destinar su mejor producción al mercado interno en competencia con la de menor calidad de un productor mayor (empresario o multinacional) y este, por volumen, determina el precio de venta del aguacate.

La segunda forma en que la competencia es fatal para los campesinos es la que ocurre entre ellos, principalmente entre pequeños e intermedios. La supeditación de la producción local a la demanda externa hace que muchos campesinos se arrojen a la producción de "lo que está dando" (aguacate) generando un incremento de la oferta y, por lo tanto, un desplome de los precios. El resultado de esta dinámica de mercado es, comúnmente, la quiebra de múltiples campesinos y el final de su aventura como empresarios o, al menos, de sus esperanzas. José Julián Osorio, campesino de Sonsón que conoce bien el despojo financiero, describe así su experiencia:

hay cosas que le dan a uno reveses fuertes, entonces uno hace una inversión grande y llega el momento en que eso no le funcionó, téngalo por seguro en que el banco no le va a decir: "no tranquilo, después me paga", no, esa gente igual [...] o si le toca poner abogado ahí mismo lo pone. Me quedó la inversión hecha pero igual ahí quedó el semitecho, pues yo ahora lo estoy aprovechando pa' uchuva, con eso estoy buscando la manera de pagar (J. Osorio, comunicación personal, 27 de febrero de 2020)

Desde la perspectiva de las clases dominantes en este contexto neoliberal, es necesario y conveniente que los campesinos se embarquen en producir ellos mismos y no solo vendan su tierra. Al hacerlo, asumen riesgos y costos de producción de los cuales se desentiende el empresario o intermediario que les compra la cosecha, generan sobreproducción garantizando suficiente mercancía para el crecimiento del negocio aguacatero y, al quebrarse, los campesinos venden barata su tierra. Finalmente, una vez eliminados del mercado, el monopolio del producto a nivel nacional queda en manos de los grandes productores, lo que les permite subir el precio. 
¿Cómo el endeudamiento campesino para su articulación al mercado se constituye en una forma de despojo? En las circunstancias descritas, las quiebras son parte de la normalidad del sistema. Banqueros y prestamistas desembolsan a condición estricta de tener tierra con qué responder o algún capital que así lo permita, una herencia, por ejemplo. Cuando el campesino se atrasa en sus pagos, que a diferencia de la cosecha son regulares, se enfrenta al asedio y las amenazas de los cobradores y, en últimas, al embargo de su tierra, lo que lo lleva a endeudarse aún más.

Así, el endeudamiento campesino, que aparece como voluntario, se convierte en una forma de despojo. No obstante, lo que en realidad acecha al financista es recuperar (con creces) el dinero que prestó, más que de la tierra. Logra esto cuando se apropia de todo el excedente que el campesino pueda producir, es decir, todo aquello que el campesino (en el periodo de duración de la deuda) obtiene más allá del mínimo para poder seguir trabajando, que es destinado al pago de sus obligaciones, lo que le significa jornadas de superexplotación en su tierra y en la de algún vecino. Como se ve, la base de la "laboriosidad", el "emprendimiento" y "cultura de la buena paga" que se le atribuye a la subjetividad campesina y antioqueña en general, tomando como base este estudio sobre el campesinado sonsoneño, está lejos de ser la dulce fábula que se suele predicar. Se trata, más de bien, de atributos producidos y reproducidos por las duras relaciones sociales desposesión y desigualdad.

Teniendo como fundamento la experiencia de conflicto, los cambios en el mercado de tierras y de alimentos, así como el endeudamiento financiero, expresan relaciones sociales de desigualdad en la lógica de acumulación y despojo. Hasta el momento, se ha presentado cómo estas relaciones, en el marco del desarrollo neoliberal a nivel local en Sonsón, que implica la articulación dependiente de la economía campesina al mercado internacional y nacional, constituyen las bases estructurales de la formación de la subjetividad campesina en los últimos veinte años.

Por otro lado, es necesario considerar que el desarrollo de la agroindustria aguacatera sobre los campesinos en Sonsón no solo es forzado; también se sustenta en fuertes dispositivos discursivos desplegados por las multinacionales y el Estado local para generar consenso al respecto. El discurso, por ejemplo, acude a narrar las maravillas del cultivo, su rentabilidad, estabilidad en precios y en proveer incentivos a los campesinos, tales como asistencia técnica, certificaciones, herramientas y subsidios estatales y de ONG, con el objetivo de hacer del municipio: "Sonsón: ciudad agroindustrial y exportadora" (Ospina, 2017).

De este modo, la autonomía productiva del campesino, que le ha sido despojada, le es reemplazada con el emprendimiento capitalista. Es así como las 
fuerzas estructurales en un contexto neoliberal, entendidas en términos de desposesión y acumulación, al forzar la inserción del campesino en el mercado, lo llevan a la subjetividad de la mímica empresarial. A continuación, se describe y analiza dicha subjetividad desde la óptica de la subalternidad.

\section{Emprendedores y asalariados}

Está claro que la "vocación emprendedora" de los campesinos sonsoneños, o por lo menos su formación durante este periodo, tiene su origen en una práctica social forzada por el despojo de las clases dominantes sobre sus explotados que alumbra el entendimiento de cómo se ha edificado el mito del "emprendedor paisa". Acorde con esto, otras características atribuidas en el pensamiento hegemónico de las élites regionales a esta subjetividad, como el trabajo abnegado, resultan idealizaciones cuyo origen está en la proletarización igualmente forzada y favorecida por una historia de precarización rural.

Entre 1997 y 2020, los campesinos de Sonsón experimentaron las relaciones de dominación frente a banqueros, comerciantes y empresarios como la desposesión de su autonomía. Este proceso estuvo mediado por el despliegue de mecanismos hegemónicos que buscaban formar una subjetividad que tiene como eje central la subalternidad sobre otras dimensiones como la autonomía o insubordinación. La subjetividad subalterna resultante tiene dos formas específicas: el emprendimiento y la afirmación del trabajo asalariado. La razón por la cual se pueden entender estos rasgos como característicos de una subjetividad subalterna está en que obedecen a la experiencia en el mundo de las clases (o sujetos) dirigentes/dominantes, a sus valores, autorepresentaciones y a cómo se imaginan a sí mismas.

Es posible dar cuenta de estos dos elementos, es decir, de cómo los campesinos afirman de palabra y con mucha seguridad, para sí, la visión del mundo de los empresarios, terratenientes, banqueros y comerciantes. Dos ejemplos de campesinos de Sonsón, uno emprendedor y otro proletarizado, sirven para ilustrar esto. José Julián Osorio, quien posee tierra y con ella se vio abocado al camino del emprendimiento articulado a la exportadora Ocati, describe así la importancia de que el mercado externo asuma el control de la producción local:

En Europa molestan mucho es por el tema de los químicos y en Estados Unidos por cualquier cosita, si le encuentran a usted un bichito así [pequeño] le queman todo el cargamento y eso es bueno, tiene que ser así porque el mercado lo pide. (J. Osorio, comunicación personal, 15 de marzo de 2020)

José Ferney Sánchez es un joven jornalero, que trabaja como agregado en una finca que es propiedad de un empresario urbano y tiene una visión optimista de su trabajo en tierra ajena: 
pero ahora donde estoy trabajando diario es como mejor porque uno tiene el sueldo ahí fijo y puede colaborar más en la casa, porque usted sacar un producto y de pronto el precio bien barato o pagar el transporte, todo eso, entonces no hay como tener el sueldo ahí uno pa' colaborar en la casa, usted semanal trabaja, es duro pero uno ahí tiene el sueldo, mientras que usted siembra una mata, la cultiva, mientras que le ve plata, mientras tanto qué, las obligaciones en la casa no dan espera. (J. Sánchez, comunicación personal, 29 de febrero de 2020)

No obstante, esta subalternización no es absoluta. Por lo tanto, sus rasgos centrales no logran desaparecer algunas de las experiencias de desposesión y explotación padecidas por los campesinos, solo que éstas no son tenidas en cuenta a la hora de narrar su maravilloso talante emprendedor y laborioso. La pérdida de autonomía fue experimentada también como la incapacidad de escoger cómo usar su tiempo, como hostigamiento por los banqueros y prestamistas, miedo a los cambios en el mercado, enfermedad asociada a la incorporación de plaguicidas; en últimas, como la negación de la posibilidad de decidir sobre su propia vida. En su mayoría, estas consecuencias son compartidas tanto por aquellos que emprendieron como por aquellos ya proletarizados. De esta manera, José Ferney narra su experiencia trabajando como jornalero en la aplicación de pesticidas a cultivos de producción para el mercado:

eso era voliando veneno de los más caros, me pegué una enfermada brava con eso, me intoxiqué siempre [...]no pues yo no le dije nada [al patrón], yo le dije que yo no podía fumigar con esos venenos bravos y no, no dijo nada, ya a lo último no me ponía a fumigar, pero pues que le va a reconocer a uno gastos médicos o así no, si uno se enfermó respóndase usted del bolsillo de lo que gane, pues es que eso es como una bomba y llenar eso de baños y unas frisoleras altas o una alverja, entonces usted bañando así y todo ese vapor así, o con la ropa usted va pasando y los hilos le van pegando baño, el olor todo eso, entonces me ponía a vomitar, como con fiebre, comía y eso el revoltijon en la barriga y como eso era semanal voliando venenos, litros de 250-300 mil pesos un litro, eso son unos venenos muy exagerados de bravos, entonces eso se enferma uno grave, yo ya me ponía que destapaban el frasco y yo ya estaba con dolor de cabeza, ya estaba hirviendo con fiebre, ya tenía desespero en la barriga. (J. Sánchez, comunicación personal, 29 de febrero de 2020)

Igualmente, José Julián Osorio, da cuenta de su tormento a manos del sistema financiero:

iHay hermano! Solamente la señora mía sabe cómo pasaba yo las noches [...] Diario lo llaman "vea le vamos a embargar", uno realmente hasta el filo, yo creo que mucha gente que se ha ahorcado o se matado por las deudas es por eso, por la presión que generan ellos y no estamos hablando solamente de la Fundación de la Mujer, el caso mío es particular, pero en otras personas de pronto es por otros bancos y otras condiciones, pero yo si hubiera estado más débil psicológicamente, seguro esta gente hubiera llegado hasta el desastre de hacerme matar, con una presión de esas tan verraca, diario, diario, diario me llamaban y casi que amenazándome que me iban a embargar. Yo a lo último ya los frentié y hasta les dije que los iba 
a demandar, porque me estaban haciendo enfermar psicológicamente por tanta presión. (J. Osorio, comunicación personal, 27 de febrero de 2020)

Este último ejemplo sirve para poner en cuestión otro de los rasgos de la subjetividad campesina en Sonsón y antioqueña en general: la "cultura de la buena paga". Más que una característica inherente a la población regional, como parecen sugerir los estudios hegemónicos sobre el modo de ser y la cultura antioqueña, el compromiso al pago de las deudas es la interiorización de una rígida relación de dominación sobre los campesinos que tiene como sustento material el despojo financiero. Incluso, esto les llega a costar la vida y resulta especialmente funcional a los intereses de prestamistas y banqueros; es decir, es un valor especialmente subalterno. Lo que nunca aparece en el relato hegemónico de la subjetividad es el sufrimiento por el endeudamiento y la exposición social como morosos que sufren muchos campesinos.

Ahora bien, el ánimo hacia el trabajo asalariado, como rasgo de la subjetividad, no es meramente de quienes teniendo tierra no la desean por los malos recuerdos que les trae del conflicto, es también de quienes nunca la han tenido, es decir, de quienes desean pasar del jornaleo al trabajo asalariado o, incluso, de quienes pudiendo acceder a la propiedad familiar escogen proletarizarse.

Este proceso de proletarización es característico de jóvenes que, ante la cada más escasa posibilidad de forjar sus vidas en el campo por las condiciones de atraso, por el vaciamiento que produjo el conflicto y por la presión del mercado (fuerzas que impiden la reproducción de la vida material), abandonan sus tierras para trabajar en los cultivos agroindustriales de la región como asalariados. Abrazan así su nueva vida y dejan las veredas en un proceso de envejecimiento, lo que supone a su vez otros cambios subjetivos, como la ruptura con la comunidad campesina, la afinidad por el dinero y la adopción más rápida de la cultura urbana (Vega y comunidades campesinas de Río Verde en Sonsón, 2019).

Así, todo lo anterior permite pensar la trasformación de la subjetividad de los campesinos de Sonsón, en este periodo, como una centralización de valores propios de las clases dirigentes y funcionales a su modelo de acumulación neoliberal que, a su vez, relega la pérdida de autonomía con todas sus expresiones, especialmente el sufrimiento campesino derivado de dicho modelo. El aniquilamiento de la autonomía permitió edificar una subjetividad subalterna basada en el empresarismo y el trabajo asalariado como horizonte de vida. En una perspectiva más amplia, esto abre la posibilidad de indagar por otras dimensiones de la experiencia subjetiva campesina en este proceso histórico que no son subalternas. 


\section{Conclusiones}

Atendiendo a la problemática inicialmente planteada, es posible afirmar que la formación o transformación de la subjetividad de los campesinos de Sonsón entre 1997 y 2020 tiene su fundamento en el desarrollo de procesos de acumulación de capital por desposesión. Estos cambios consistieron en la afirmación y desarrollo de una subjetividad subalterna, es decir, en la interiorización campesina de los intereses, valores y visión del mundo de sujetos sociales que agenciaron estas formas de acumulación y que fueron funcionales a ese modelo. La subalternización resultante, a la vez, ha relegado de la subjetividad campesina hegemonizada el sufrimiento por el modelo de acumulación, así como sus esfuerzos o potencialidades por la autonomía e insubordinación.

El conflicto social armado, y más exactamente la correlación de fuerzas resultante a favor de los agentes del desarrollo neoliberal —empresarios, multinacionales, terratenientes, industriales y comerciantes - en el periodo entre 1997 y 2010, es la base que permite el desarrollo de las condiciones objetivas de la "nueva" subjetividad campesina, porque barre con los obstáculos a su desarrollo, como la oposición de sujetos sociales antagónicos al modelo.

La afirmación o gestación de la subjetividad subalterna en los campesinos de Sonsón ha tenido, en el periodo en cuestión, tres rasgos fundamentales: el emprendimiento capitalista en condiciones rurales como una virtud, el abrazo al trabajo asalariado como forma más elevada de vida y la reivindicación de la "cultura de buena paga" como sacrificio abnegado en función del sistema financiero. Estos rasgos son, precisamente, representaciones y prácticas funcionales al modelo de acumulación neoliberal en general y a sus formas en particular.

Concretamente, los procesos de acumulación que dieron pie a estos cambios en la subjetividad hacen parte de la integración forzada de la economía campesina de Sonsón al mercado mundial y nacional de alimentos a un nivel más agresivo y dependiente. Su eje es el desarrollo de la agroindustria aguacatera y, en general, de alimentos para el mercado externo. A ello se vinculan la desposesión de la tierra por medio de la compra que hacen empresarios y multinacionales, así como la quiebra campesina a manos del mercado y su endeudamiento; todo esto desemboca en un proceso de proletarización.

El trabajo base del que deriva el presente artículo incluye el análisis de la trasformación del aparto cultural local en Sonsón durante este periodo, de las organizaciones campesinas y de la manera en que los intelectuales locales han representado la vida campesina. Todo esto amplía el entendimiento de cómo la dimensión política (entendida en términos de generación de consenso) y cultural 
del conflicto social han mediado entre la experiencia campesina de las relaciones de dominación y su interiorización.

El estudio de la subjetividad campesina en Antioquia puede aportar al entendimiento de la subjetividad regional si se considera que varias de sus propiedades atribuidas se formaron históricamente a partir de la subsunción del campo a la ciudad y del desarrollo de relaciones sociales capitalistas en la ruralidad. Por lo anterior, resulta pertinente y queda abierta la pregunta por la pretensión universal de dicha subjetividad o de cómo ésta ha alimentado un proyecto de nación de clases sociales dirigentes. De esta manera, se puede profundizar en un análisis específico de la hegemonía y sus medios sobre el campesinado.

En este sentido, este artículo y la investigación que le sirve de fuente aportan al debate sobre la formación de las subjetividades, la antioqueña en este caso, a partir de una perspectiva para su entendimiento que es indisoluble de las condiciones estructurales históricamente formadas y sobre todo conflictivas. Con ello, se controvierten las postulaciones hegemónicas al respecto que tienen principalmente un carácter subjetivista e idealizado.

Este trabajo sitúa la experiencia de los sujetos dentro de la estructura social que se caracteriza por relaciones de desigualdad y poder. Así, postula (o al menos indicia) una contestación a las explicaciones hegemónicas sobre la subjetividad y el modo de ser regional, que reproducen una idealización del despojo y la explotación o entienden los procesos de acumulación (con otros nombres) a partir del talante de la población. En definitiva, contribuye a alumbrar cómo la "vocación emprendedora" antioqueña, tomando el caso aquí estudiado, esconde la historia de vida de seres humanos arrojados forzada y violentamente a la lucha por la sobrevivencia.

\section{Agradecimientos}

Agradezco a la profesora Carmen Gómez Martín por su esfuerzo de revisión, aportes y críticas como asesora de la tesis en que se basa este artículo, que tuvo lugar en la maestría en Sociología de la Facultad Latinoamericana de Ciencias Sociales (Flacso), Ecuador. La investigación se denominó Imposición de la Subalternidad sobre el campesinado en el marco de procesos de acumulación y hegemonía. El caso del municipio de Sonsón, subregión del oriente de Antioquia (Colombia) 1997-2020. Actualmente (abril de 2020) la tesis se encuentra aprobada. 


\section{Referencias}

Appelbaum, N. (2007). Dos plazas y una nación: raza y colonización en Riosucio, Caldas, 1846-1948. Universidad del Rosario; ICANH.

Arbeláez, A. (2007). El Oriente Antioqueño. En Corporación Región (ed.), Migración Forzada de Colombianos: Colombia, Ecuador, Canadá (pp. 113-147). Corporación Región.

Betancur, B. (1987). Declaración de amor del modo de ser antioqueño. El Navegante Editores

Correa, F. y Jaramillo, J. (2002). El ethos antioqueño: Soporte moral para la creación, desarrollo y conservación de empresas. Semestre Económico 5(10), 1-20. https://revistas.udem.edu.co/index.php/ economico/article/view/1382

Federici, S. (2010). Calibán y la bruja. Mujeres, cuerpo y acumulación primitiva. Traficantes de Sueños.

Gramsci, A. (1967). La formación de los intelectuales. Editorial Grijalbo.

Gramsci, A. (2013). Algunos temas sobre la cuestión meridional. En M. Sacristán (ed.), Antología (pp. 365-374). Editorial Akal.

Gutiérrez, V. (1999). Familia y cultura en Colombia. Editorial Universidad de Antioquia.

Harvey, D. (2005). El "nuevo" imperialismo: acumulación por desposesión. En L. Panitch y C. Layes (eds.), Socialist Register 2004. El nuevo desafío imperial (pp. 99-130). Clacso. http://biblioteca. clacso.org.ar/clacso/se/20130702120830/harvey.pdf

Luxemburgo, R. (1912). La acumulación de capital. Edicions internacionals Sedov. Germinal. https:// www.marxists.org/espanol/luxem/1913/1913-lal-acumulacion-del-capital.pdf

Marx, K. (1974). El Capital, crítica de la economía política, Tomo 1. Fondo de Cultura Económica.

Microempresas de Colombia. (2019). Estudio de factibilidad apertura de oficina Sonsón-Antioquia. https://bit.ly/36iDD1q

Modonesi, M. (2010). Subalternidad, antagonismo, autonomía. Marxismo y subjetivación política. Clacso.

Olaya, C. (2016). El exterminio del Movimiento Cívico del Oriente de Antioquia. El ágora, 17(1), 128-144. http://www.scielo.org.co/pdf/agor/v17n1/v17n1a07.pdf

Ospina, J. (2017, 27 de abril). El municipio de Sonsón se perfila como potencia en la exportación de aguacate Hass. Alcaldía de Sonsón. http://sonson-antioquia.gov.co/NuestraAlcaldia/SaladePrensa/ Paginas/El-municipio-de-Sons\%C3\%B3n-se-perfila-como-potencia-en-la-exportaci\%C3\%B3n-deaguacate-hass.aspx

Palacios, M. (2009). El café en Colombia, 1850-1970: Una historia económica, social y política. El Colegio de México.

Siegert, C. y de la Torre, C. (2011). Geografías de la Guerra, el Poder y la Resistencia: Oriente y Urabá Antioqueños, 1990-2008. Cinep.

Téllez, J. (2010). La colonización antioqueña, el emprendimiento, y su aporte a la competitividad regional y nacional. Estudios Gerenciales, 26(114) 119-147. https://www.redalyc.org/articulo.oa?id=21218572006

Tirado, Á. (1979). Aspectos de la Colonización Antioqueña. Revista de Extensión Cultural, (7). 20-27. https:// repositorio.unal.edu.co/handle/unal/57280

Vega, Y. y Comunidades campesinas de Río Verde Sonsón. (2019). Río Verde de los Montes: tierras de hermandad, alegría y trabajo. Universidad Eafit. 